\title{
Intraductal papilloma of the breast - management
}

\author{
Diana Hodorowicz-Zaniewska ${ }^{1,2}$, Joanna Szpor ${ }^{2,3}$, Pawel Basta ${ }^{2,4}$ \\ ${ }^{1} 1^{\text {st }}$ Chair of General Surgery, Department of General, Oncological and Gastroenterological Surgery, \\ Jagiellonian University Medical College, Cracow, Poland \\ 2University Center for Breast Diseases, University Hospital in Cracow, Poland \\ ${ }^{3}$ Chair of of Pathomorphology, Jagiellonian University Medical College, Cracow, Poland \\ ${ }^{4}$ Chair of Gynaecology and Obstetrics, Department of Gynaecology and Oncology, \\ Jagiellonian University Medical College, Cracow, Poland
}

\begin{abstract}
In light of the growing availability of ultrasound testing and invasive diagnostic methods of the breast in everyday gynecologic practice, lesions of uncertain malignant potential, classified histologically as B3, have become a significant health issue. Intraductal papillomas (IPs) are the most common pathology in that group of lesions. Despite their benign histologic appearance, IPs may accompany malignant growths and the diagnosis made on the basis of biopsy material carries the risk of breast cancer $(\mathrm{BC})$ underestimation. The article presents a review of the available literature on the management of patients diagnosed with intraductal papilloma at a standard core needle biopsy or vacuum-assisted core needle biopsy. The management is not uniform and depends not only on the verification technique or the accompanying pathological growths, but also on the result of clinical-pathological correlations. As it turns out, open surgical biopsy should not necessarily be recommended to every affected woman, and a growing number of sources have recently suggested that a control program would be sufficient in many cases. Thus, it is vital for gynecologists to be able to differentiate between those women who may be included in the annual ultrasound control program and those who require further surgical management.

Key words: intraductal papilloma; B3 breast lesions; core needle biopsy; vacuum-assisted core needle biopsy;
\end{abstract} underestimation; breast cancer

Ginekologia Polska 2019; 90, 2: 100-103

\section{INTRODUCTION}

Ultrasound imaging of the breast is one of the components of complex gynecologic care offered to a patient. In Poland, as in many other European countries, gynecologic care is not limited to secondary prevention of breast cancer, and the number of gynecologists who perform histopathological verification of the focal lesions using different biopsy techniques continues to grow. Thus, it is vital that they are able to interpret the histologic result of a biopsy, conduct clinical-pathological correlations, and identify those patients who require further surgical management. An intraductal papilloma (IP), a benign growth originating from the epithelium of the milk duct, is an example of a problematic histologic diagnosis. Owing to its heterogeneity and the risk for coexisting malignant growths, IP is classified as B3, i.e. a lesion of uncertain malignant potential [1].
Over the last century, the management of patients diagnosed with IPs has undergone a radical change. Initially, clinical suspicion of IP, with an accompanying sanguinous nipple discharge, was a direct indication for mastectomy. In the years to follow, segmental resection of the breast tissue, removal of the papillary tissue or isolated resection of the milk ducts, have been recommended [2]. The abovementioned radical management was directly responsible why nipple discharge, especially sanguinous, was believed to be indicative of malignant neoplasm of the breast for decades. Nowadays, in the era of advanced diagnostic techniques and minimally invasive procedures, the number of indications for surgical management of IP has notably decreased. Apparently, open surgical biopsy should not necessarily be recommended to all patients with IP and numerous publications suggest that follow-up program would be sufficient in many cases. 


\section{EPIDEMIOLOGY}

Intraductal papillomas (IPs) constitute approximately $10 \%$ of all benign growths within the breast [3]. Their incidence has been estimated at 2-3\% among the female population, but the risk increases to $40-70 \%$ in case of nipple discharge [4]. Papillomas may develop in women of all ages, most often between 30-77 years of age [5]. Almost $90 \%$ of IPs are central, single lesions localized within the large collective ducts, usually developing in the older women and manifesting as nipple discharge (serous, serosanguinous, or sanguinous) [6]. Coexisting atypical growths are rare and IPs do not significantly increase the risk for the development of BC (breast cancer) [7]. Peripheral papillomas are significantly less common; they usually develop in young women and typically have multiple, occasionally bilateral, presentation. They may present as palpable tumors but are most often clinically silent, and are diagnosed accidentally during preventive screening tests [8]. Unlike central papillomas, they usually coexist with atypical growths, e.g. atypical ductal hyperplasia (ADH), atypical lobular hyperplasia (ALH), lobular carcinoma in situ (LCIS), or even ductal carcinoma in situ (DCIS), and notably increase the risk for developing invasive breast cancer [8-10].

\section{ULTRASOUND AND PATHOLOGY DIAGNOSIS}

Intraductal papillomas have various imaging presentations, from hyperechogenic growths in the ducts or cysts, to hypoechogenic, well-differentiated hypervascular solid masses $[5,11]$. In some cases, IP morphology may resemble that of clustered breast microcysts [12] (Fig. 1).

As far as pathology is concerned, papillary lesions include hyperplastic lesions, presumably benign or malignant tumors. Benign presumed neoplastic papillary lesions include large duct papilloma, peripheral duct papilloma,

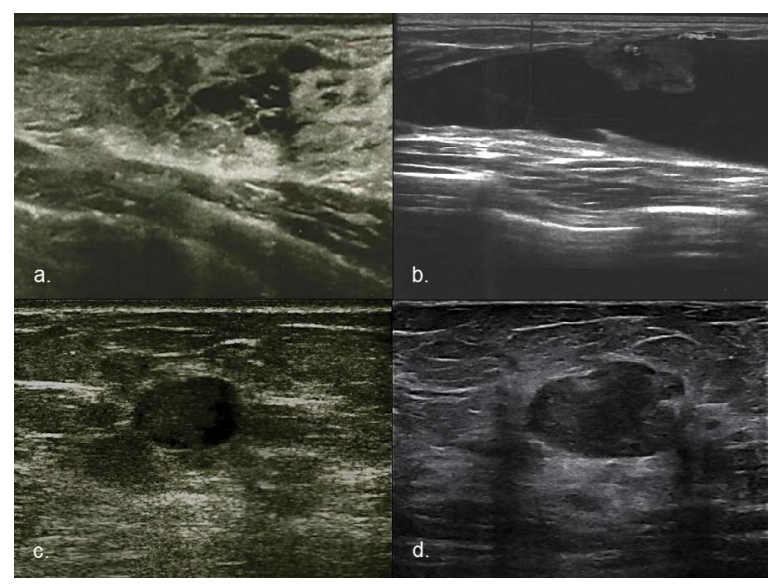

Figure 1. Intraductal breast papilloma images in ultrasound $\mathbf{a}$-clustered microcysts; $\mathbf{b}$ - hyperechogenic mural nodule in the major milk duct; c - hyperechogenic growth in the cyst; d-hypoechogenic solid mass sclerosing papilloma, nipple adenoma, papilloma with low-grade neoplastic atypia and rare adenomyoepithelioma with papillary morphology $[13,14]$. Structurally, they bear resemblance to papillary malignant lesions such as low-grade papillary DCIS, encapsulated papillary carcinoma or solid papillary carcinoma, and the use of immunohistochemistry is required in differential diagnosis [14]. Significant heterogeneity of papillary lesions is the reason why fine needle aspiration biopsy is not applicable in the diagnosis of IPs (high rate of false negative results), and even core needle biopsy presents a challenge for the pathologist [14]. In contrast, a vacuum-assisted core needle biopsy may generate an almost unlimited number of specimens. In terms of tissue volume, vacuum-assisted core needle biopsy is more similar to surgical biopsy than core needle biopsy, and its diagnostic accuracy reaches $98-100 \%$ [15]. Nevertheless, material fragmentation makes it impossible to determine the histologic evaluation of resection margins.

\section{INTRADUCTAL PAPILLOMA DIAGNOSED AT BIOPSY — THE NEXT STEPS}

The diagnosis of intraductal papilloma at biopsy requires careful management. First, sample representativeness needs to be evaluated, followed by the analysis of adequate clinical-pathological correlations, meaning that a reanalysis of the biopsy material needs to be performed to verify whether the result corresponds to the most probable diagnosis made on the basis of the imaging tests. That particular course of action is undertaken due to the significant heterogeneity of the lesions in question. In case of doubt, the biopsy should be repeated, or surgical excision should be performed.

The method of verification is the next parameter to be considered. The literature reports indicate that the diagnosis of intraductal papilloma without atypia at a standard core needle biopsy is associated with a $2.3-16 \%$ risk of $B C$ underestimation $[16,17]$. Despite the fact that some authors, in case of clinical pathological concordance, advocate in favor of follow-up program [18], most clinicians lean towards radical local excision, either with the use of vacuum-assisted core biopsy or open surgical biopsy [19, 20]. When IP is accompanied by atypical ductal hyperplasia, the risk for BC underestimation increases to $13-92 \%$, in which case surgical excision is common practice $[3,21]$. The rate of false negative results for breast cancer at core needle biopsy is distinctly lower and has been estimated at 0\%-2.6\% for IPs without atypia [22,23], and at 9-21\% for IPs with accompanying atypia $[24,25]$. According to the current recommendations, surgical excision is still mandatory in case of atypical lesions, whereas vacuum-assisted core needle biopsy may be considered as a therapeutic option in case of IPs without atypia, on condition that a 5-year follow-up program is implemented [21, 22] (Fig. 2). 


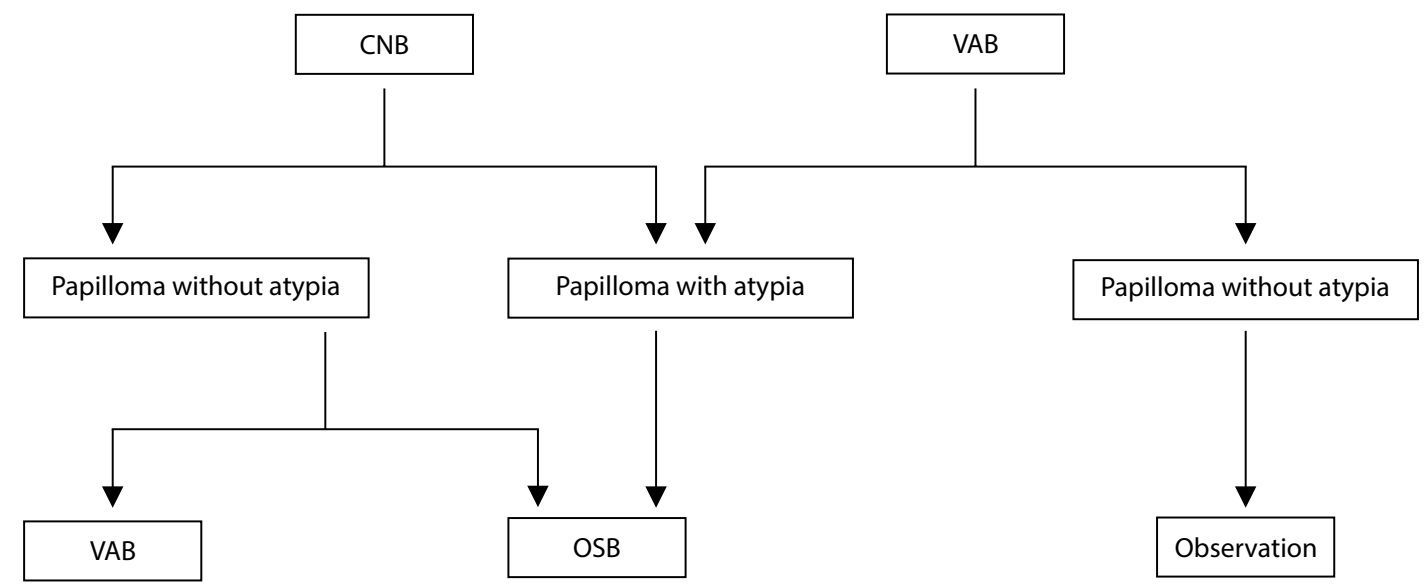

CNB-core needle biopsy, VAB-vacuum-assisted biopsy, OSB-open surgical biopsy

Figure 2. Recommendations for intraductal breast papilloma on core biopsy

\section{CONCLUSIONS}

According to the literature, after the diagnosis of IP without atypia at a standard core needle biopsy, surgical excision, either using vacuum-assisted core needle biopsy or open surgical biopsy, should be immediately recommended. Both methods have high reliability and although the biopsy method does not allow for histologic evaluation of the resection margins, lower invasiveness of the procedure is an undeniable asset. In case of primary vacuum-assisted core needle biopsy and clinical pathological concordance, the management may be considered as definitive. Still, it is vital to remember about the annual ultrasound follow-up for the affected women, not only due to the risk for recurrence but also for the development of breast cancer. Regardless of the verification method, the diagnosis of intraductal papilloma with atypia at biopsy is always and without question an indication for further surgical management.

\section{REFERENCES:}

1. Ellis IO, Humphreys S, Michell M, et al. UK National Coordinating Commmittee for Breast Screening Pathology, European Commission Working Group on Breast Screening Pathology. Best Practice No 179. Guidelines for breast needle core biopsy handling and reporting in breast screening assessment. J Clin Pathol. 2004; 57(9): 897-902, doi: 10.1136/jcp.2003.010983, indexed in Pubmed: 15333647.

2. Dennis MA, Parker S, Kaske TI, et al. Incidental treatment of nipple discharge caused by benign intraductal papilloma through diagnostic Mammotome biopsy. AJR Am J Roentgenol. 2000; 174(5): 1263-1268, doi: 10.2214/ajr.174.5.1741263, indexed in Pubmed: 10789774

3. Boufelli G, Giannotti MA, Ruiz CA, et al. Papillomas of the breast: factors associated with underestimation. Eur J Cancer Prev. 2018; 27(4): 310-314, doi: 10.1097/CEJ.0000000000000343, indexed in Pubmed: 28296665.

4. Paterok EM, Rosenthal H, Säbel M. Nipple discharge and abnormal galactogram. Results of a long-term study (1964-1990). Eur J Obstet Gynecol Reprod Biol. 1993; 50(3): 227-234, indexed in Pubmed: 8262300.

5. Ganesan S, Karthik G, Joshi M, et al. Ultrasound spectrum in intraductal papillary neoplasms of breast. Br J Radiol. 2006; 79(946): 843-849, doi: 10.1259/bjr/69395941, indexed in Pubmed: 16641415.

6. Al Sarakbi W, Worku D, Escobar PF, et al. Breast papillomas: current management with a focus on a new diagnostic and therapeutic modality. Int
Semin Surg Oncol. 2006; 3(1): 1-8, doi: 10.1186/1477-7800-3-1, indexed in Pubmed: 16417642.

7. Jacobs TW, Connolly JL, Schnitt SJ. Nonmalignant lesions in breast core needle biopsies: to excise or not to excise? Am J Surg Pathol. 2002; 26(9): 1095-1110, indexed in Pubmed: 12218567.

8. Maxwell AJ. Ultrasound-guided vacuum-assisted excision of breast papillomas: review of 6-years experience. Clin Radiol. 2009; 64(8): 801-806, doi: 10.1016/j.crad.2009.04.007, indexed in Pubmed: 19589419.

9. Bonaventure T, Cormier B, Lebas $\mathrm{P}$, et al. [Benign papilloma: is US-guided vacuum-assisted breast biopsy an alternative to surgical biopsy?]. J Radiol. 2007; 88(9 Pt 1): 1165-1168, indexed in Pubmed: 17878878.

10. Haagensen $C D$, Bodain $C$, Haagensen DE. Breast carcinoma risk and detection. WB Saunders, Philadelphia 1981: 146.

11. Brookes MJ, Bourke AG. Radiological appearances of papillary breast lesions. Clin Radiol. 2008; 63(11): 1265-1273, doi: 10.1016/j. crad.2008.02.012, indexed in Pubmed: 18929044.

12. Athanasiou A, Aubert E, Vincent Salomon A, et al. Complex cystic breast masses in ultrasound examination. Diagn Interv Imaging. 2014; 95(2): 169-179, doi: 10.1016/j.diii.2013.12.008, indexed in Pubmed: 24433921.

13. Hoda S, Kaplan R. World Health Organization (WHO) Classification of Breast Tumours, 4th ed. The American Journal of Surgical Pathology. 2013; 37(2): 309-310, doi: 10.1097/pas.0b013e318273b19b.

14. Agoumi M, Giambattista J, Hayes MM. Practical Considerations in Breast Papillary Lesions: A Review of the Literature. Arch Pathol Lab Med. 2016; 140(8): 770-790, doi: 10.5858/arpa.2015-0525-RA, indexed in Pubmed: 27472236.

15. Nakano S, Sakamoto $H$, Ohtsuka $M$, et al. Evaluation and indications of ultrasound-guided vacuum-assisted core needle breast biopsy. Breast Cancer. 2007; 14(3): 292-296, indexed in Pubmed: 17690507.

16. Pareja F, Corben AD, Brennan SB, et al. Breast intraductal papillomas without atypia in radiologic-pathologic concordant core-needle biopsies: Rate of upgrade to carcinoma at excision. Cancer. 2016; 122(18): 2819-2827, doi: 10.1002/cncr.30118, indexed in Pubmed: 27315013.

17. Leithner D, Kaltenbach B, Hödl P, et al. Intraductal Papilloma Without Atypia on Image- Guided Breast Biopsy: Upgrade Rates to Carcinoma at Surgical Excision. Breast Care (Basel). 2018; 13(5): 364-368, doi: 10.1159/000489096, indexed in Pubmed: 30498423.

18. Kiran $\mathrm{S}$, Jeong YJu, Nelson ME, et al. Are we overtreating intraductal papillomas? J Surg Res. 2018; 231: 387-394, doi: 10.1016/j.jss.2018.06.008, indexed in Pubmed: 30278958.

19. Khan S, Diaz A, Archer KJ, et al. Papillary lesions of the breast: To excise or observe? Breast J. 2018; 24(3): 350-355, doi: 10.1111/tbj.12907, indexed in Pubmed: 28845569.

20. Shiino S, Tsuda H, Yoshida M, et al. Intraductal papillomas on core biopsy can be upgraded to malignancy on subsequent excisional biopsy regardless of the presence of atypical features. Pathol Int. 2015; 65(6): 293-300, doi: 10.1111/pin.12285, indexed in Pubmed: 25801805.

21. Am Soc Breast Surg: Consensus guideline on concordance assessment of image-guided breast biopsies and management of borderline or high-riskle- 
sions. Nov2, 2016. https://www.breastsurgeons.org/new layout/about/statements/PDF_Statements/Concordance_and_High\%20RiskLesions.pdf.

22. Rageth CJ, O'Flynn EAm, Comstock $C$, et al. First International Consensus Conference on lesions of uncertain malignant potential in the breast (B3 lesions). Breast Cancer Res Treat. 2016; 159(2): 203-213, doi: 10.1007/s10549-016-3935-4, indexed in Pubmed: 27522516.

23. Mosier AD, Keylock J, Smith DV. Benign papillomas diagnosed on large-gauge vacuum-assisted core needle biopsy which span <1.5 cm do not need surgical excision. Breast J. 2013; 19(6): 611-617, doi: 10.1111/tbj.12180, indexed in Pubmed: 24102818.
24. Chang JM, Han W, Moon WK, et al. Papillary lesions initially diagnosed at ultrasound-guided vacuum-assisted breast biopsy: rate of malignancy based on subsequent surgical excision. Ann Surg Oncol. 2011; 18(9): 2506-2514, doi: 10.1245/s10434-011-1617-3, indexed in Pubmed: 21369740.

25. Saladin C, Haueisen H, Kampmann G, et al. MIBB Group. Lesions with unclear malignant potential (B3) after minimally invasive breast biopsy: evaluation of vacuum biopsies performed in Switzerland and recommended further management. Acta Radiol. 2016; 57(7): 815-821, doi: 10.1177/0284185115610931, indexed in Pubmed: 26552694. 